\title{
Novel simple method for preparing tailored polymer-titania nanotubes
}

\section{hybrid materials}

Javier Marugán $^{\text {a,b,*, }}$, Cintia Casado ${ }^{\text {a,b }}$, Gregory Silverberg ${ }^{b}$, Chad D. Vecitis ${ }^{b}$

${ }^{a}$ Department of Chemical and Environmental Technology (ESCET), Universidad Rey

Juan Carlos, C/ Tulipán s/n, 28933 Móstoles, Madrid, Spain.

${ }^{\mathrm{b}}$ School of Engineering and Applied Sciences, Harvard University, Cambridge, Massachusetts 02138, United States

\begin{abstract}
A novel method for preparing hybrid polymer-titania nanotube (TNT) arrays with promising optical, catalytic and filtration applications is reported. The procedure is based on a one-step rapid galvanostatic anodization followed by the transfer of the TNT arrays to a polymer support by applying heat and pressure. The fraction of open-ended tubes can be controlled by changing the intensity of the current at the end of the anodization step. For example, completely open-ended or close-ended TNT arrays can be obtained by applying high or low current intensity, respectively at the end of the anodization process. The reported procedure allows the one-step simple and rapid preparation of flexible hybrid polymer-TNT materials which have great potential for photonic flow-through membranes.
\end{abstract}

Keywords: titania nanotube, polymer, membrane, hybrid material, anodization

* E-mail: javier.marugan@ urjc.es. Phone: +34 916647466

\section{Introduction}

Titania nanotube (TNT) attracts significant research interest due to their interesting optical and catalytic properties that have promising potential applications in solar cells [1], fuel cells [2], chemical sensors [3], water splitting [4,5] photocatalytic processes $[6,7]$ and biomedical applications [8,9]. From the different methods reported in the literature to prepare TNT-based materials [10], the electrochemical anodization of titanium has been extensively studied as a method to form highly ordered arrays of TNT. Since the electrochemical growth of TNT by anodization of titanium in fluoride containing electrolytes was first reported by Zwilling and co-workers [11], researchers have focused on understanding the mechanism of the process [12], the effect of the 
process variables on the morphological parameters of the synthesized TNT [13], the effect of the metal alloy composition [14] and the comparison between potentiostatic and galvanostatic conditions [15]. Incorporation of TNT to plastics has also been reported by anodization of a previously deposited titanium thin layer [3,16] (bottom closed TNT) or by incorporating hydrothermally synthesized TNT (disordered) to polymer membranes [2,17].

Preparation of flow-through $\mathrm{TiO}_{2}$ nanotube arrays have been reported to be possible by different procedures [18], including the decrease [19] or the increase [20] of the voltage at the end of a two-step potentiostatic anodization process. In this work, a novel simple method for preparing polymer-TNT arrays hybrid materials using a one-step rapid galvanostatic method is reported. A fine tune of the current and time at the end of the anodization step allow the control of the tube opening process, leading to tailored materials with completely open or close-ended TNT that can be successfully transferred to flexible polymer substrates by applying heat and pressure.

\section{Material and Methods}

TNT arrays were prepared by anodization of titanium foils (Trinity Brand Industries Grade 2 \#6T-5, thickness 0.005 in) in an ethylene glycol electrolyte containing $0.15 \mathrm{M}$ $\mathrm{NH}_{4} \mathrm{~F}$ (Sigma-Aldrich, >98\%) and $5 \mathrm{wt} \%$ deionized water. Prior to the treatment, titanium pieces were degreased by ultra-sonication in ethanol for $15 \mathrm{~min}$ and covered with Scotch tape to frame $4 \mathrm{~cm}^{2}$ of exposed surface. Anodization was carried out in a stirred $100 \mathrm{~mL}$ volume two-electrode cell using a $4 \times 6 \mathrm{~cm}$ stainless steel sheet as counter electrode placed in a centered position regarding the anode at a distance of 2 $\mathrm{cm}$. The cell was immersed in an ice bath to keep temperature at $0^{\circ} \mathrm{C}$ even when applying high intensity currents. An Agilent Technologies N5750A System DC Power Supply with maximum values of $150 \mathrm{~V}$ and $5 \mathrm{~A}$ was used to carry out the anodization under galvanostatic control at a current density value of $0.025 \mathrm{~A} / \mathrm{cm}^{2}$ for $30 \mathrm{~min}$, followed by a final step of sudden increase or decrease of the current value.

Transfer of the TNT array to the polymer substrate (nylon membrane filters, 0.45 $\mu \mathrm{m}, 47 \mathrm{~mm}$ in diameter, Omicron Scientific 170047X) was conducted using a Carver bench top heated press model 4386. Optimal conditions for the transfer were found to be $20 \mathrm{bar}, 55^{\circ} \mathrm{C}$ and $30 \mathrm{~min}$, although those values strongly depend on the polymer.

SEM images were obtained using a Zeiss Supra55VP FESEM at $5 \mathrm{kV}$ with the inlens detector. Samples were previously coated with a $10 \mathrm{~nm} \mathrm{Pt/Pd} \mathrm{conductive} \mathrm{layer.}$ 


\section{Results and Discussion}

Galvanostatic anodization of the titanium foil led to the rapid growth of a titania nanotube layer. Optimal conditions to form well-ordered TNT layers several microns in thickness were found to be 30 minutes at a current density of $0.25 \mathrm{~A} \mathrm{~cm}^{-2}$. Higher currents leads to the formation of a nonhomogeneous layer and total corrosion of some areas of the titanium sheet, whereas shorter anodization times impact the ordered structure of the TNT arrays. Figure 1 shows the evolution of the voltage and current density along the anodization process. Initially, a low potential $(\sim 20 \mathrm{~V})$ is enough to keep the current density set point. A drastic increase in the voltage to values close to $80 \mathrm{~V}$ was observed after two minutes, due to the increase in the resistance due to formation of a compact $\mathrm{TiO}_{2}$ layer. Subsequently, fluoride attack on the $\mathrm{TiO}_{2}$ layer limits the global electrical resistance of the TNT layer, resulting in a slow linear potential increase to around $100 \mathrm{~V}$ during the remaining anodization time. As a result, the proposed galvanostatic anodization reduces significantly the required anodization time in comparison with the commonly reported potentiostatic formation of TNT.

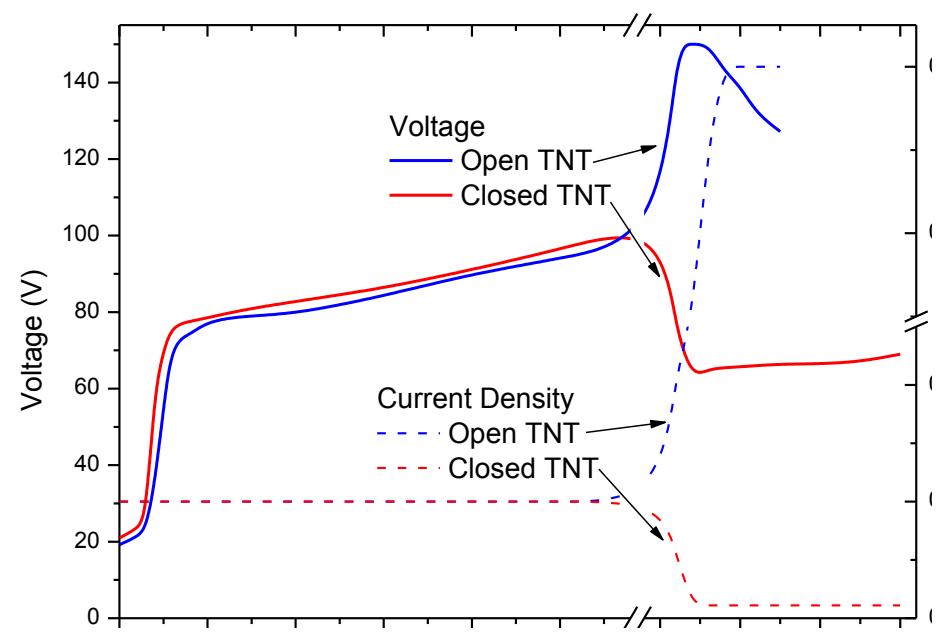

Figure 1. Time profiles of current and voltage during the anodization of samples to obtain transferred arrays of close- and open-ended TNT.

Figure 1 also shows the rapid change in the voltage and electrical current applied at the end of the process. A fast decrease in the anodization current allows the separation of closed TNT from the support whereas a fast increase in the current leads to the opening of the tubes, which will be discussed below.

Transfer of TNT to the polymer material is achieved by a hot press. Figure 2 depicts the photographs of the TNT before and after transfer to the polymer membrane. The conditions for the transfer have to be carefully optimized depending on the polymer 
characteristics, such as glass transition temperature. The goal is getting the TNT anchored to fiber structure of the polymer without clogging the pores. In the case of the nylon membranes employed in this study, best results were obtained upon application of $20 \mathrm{bar}$ and $55^{\circ} \mathrm{C}$ for $30 \mathrm{~min}$. Stronger conditions of temperature, pressure or time lead to the partial melting of the polymer with a significant reduction in the porosity. The use of methanol or other solvent to assist the detachment process is not recommended, as it prevents adhesion to the polymer.

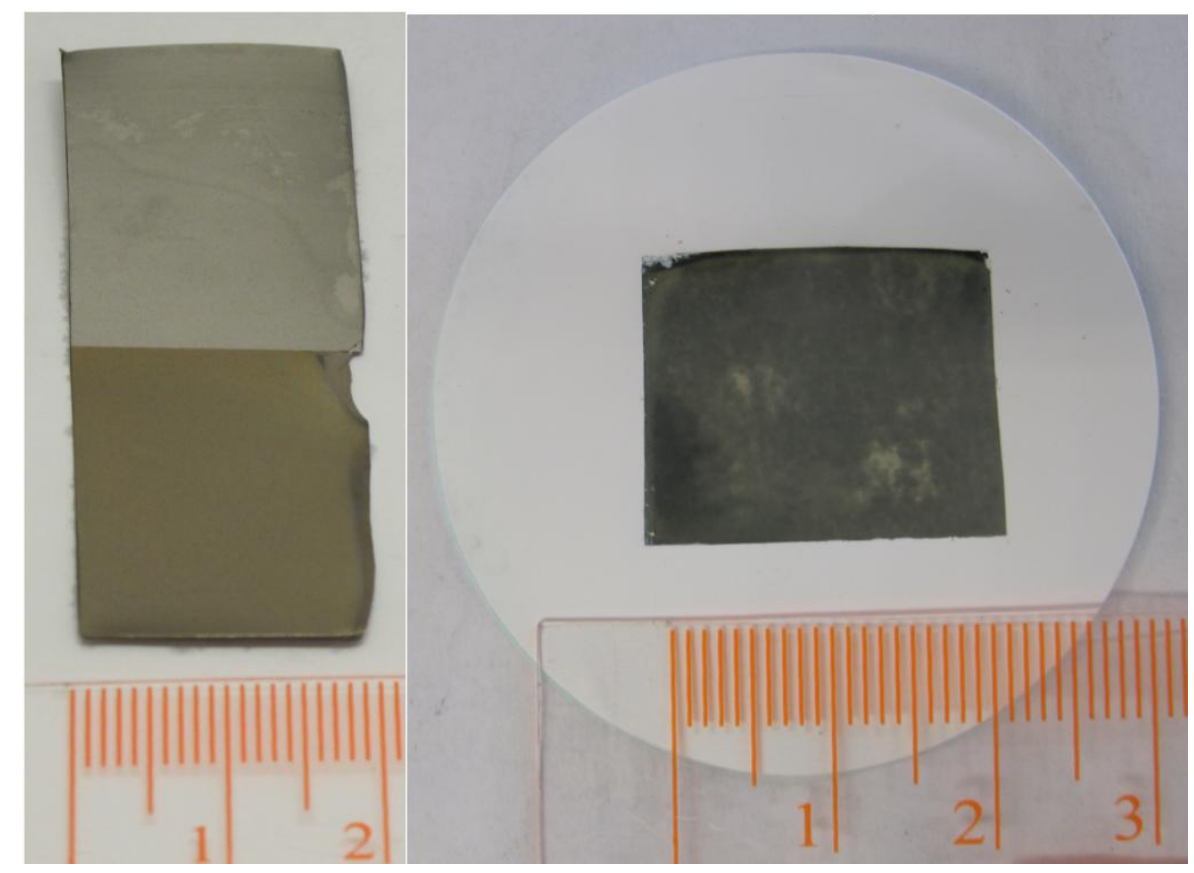

Figure 2. Photograph of a TNT array before (left) and after (right) the transfer to the polymer.

SEM images of the prepared polymer-TNT hybrid materials are shown in Figure 3. Fast reduction of the current density to $0.00275 \mathrm{~A} \mathrm{~cm}^{-2}$ during $90 \mathrm{~s}$ at the end of the anodization process led to TNT layers with closed tubes (Figure 3a and 3b), On the other hand, a fast increase in the current density up to $0.025 \mathrm{~A} \mathrm{~cm}^{-2}$ for $30 \mathrm{~s}$ is enough to generate open-ended TNT (Figure 3e and 3f) and weaken the anchorage of the TNT to the titanium foil. Longer times and/or higher intensities could lead to the loss of the TNT layer by complete detachment to the electrolyte in the electrochemical cell. On the other hand, lower intensity and/or time could lead to a partial opening of the tubes, as shown in Figure 3c and 3d). The success of the transfer can be easily assessed with the naked eye: open TNT surfaces are completely matt whereas closed TNT surfaces show a remarkable brightness. 
Figure 4 schematized the mechanism of the process. Nanotube formation is the result of a dynamic process involving the electrochemical oxidation of titanium to titanium oxide and the dissolution of titanium oxide by fluoride etching [21].

Galvanostatic anodization leads to the rapid formation of a highly ordered TNT layer growing at a constant rate that depends on the applied current intensity as a result of a stationary equilibrium between the electrochemical oxidation and the fluoride attack reaction rates. However, a sudden change in the current intensity produce a nonstationary disequilibrium between both processes with a dramatic impact on the TNT attachment region. A sudden decrease of the current reduces the rate of the electrochemical oxidation in favor of the fluoride attack reaction rate, weakening the adhesion of the tubes to the $\mathrm{TiO}_{2}$ barrier layer. In contrast, a rapid increase in the current triggers the rate of the titania oxidation, weakening the structure of the TNT walls in the region close to the support that breaks during the transfer process opening the tubes. As a result, hybrid polymer-TNT materials are produced with both open and closed TNT which are recognizable with the naked eye due to their different optical properties.In conclusion, the reported procedure allows the one-step simple and rapid preparation of flexible hybrid polymer-TNT materials which have great potential for photonic flowthrough membranes. 

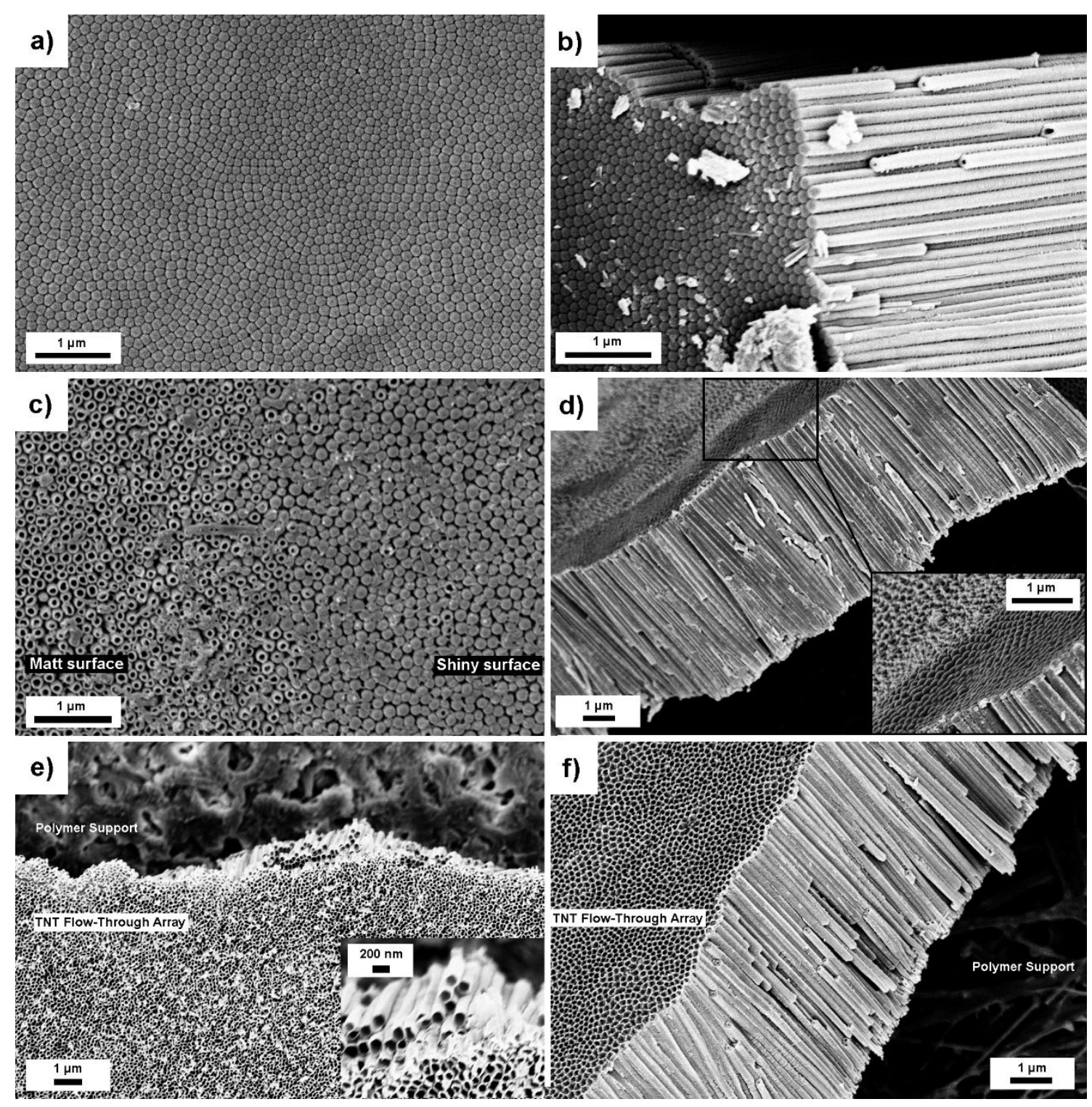

Figure 3. SEM images of the transferred TNT arrays produced after a decrease in the current intensity, a) and b), a short increase in the current intensity, c) and d), and a increase of the current intensity for an optimal duration for tube opening, e) and f). 


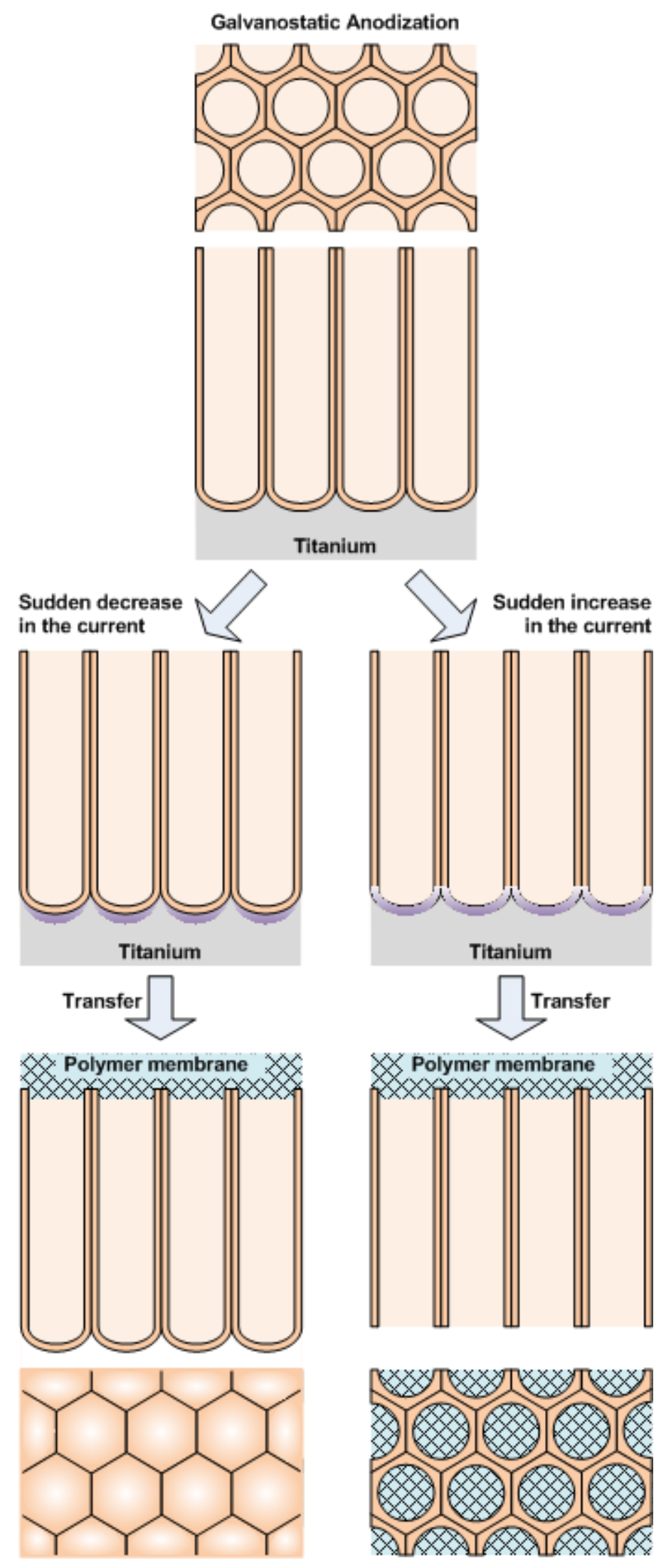

Figure 4. Schematic representation of the procedure for preparing the tailored hybrid polymer-TNT materials (see details in text). 


\section{Acknowledgments}

The authors gratefully acknowledge the financial support provided by Spanish Ministry of Economy and Competitiveness (MINECO) through the WATER4FOOD project (CTQ2014-54563-C3-1). J.M. would like to acknowledge the financial support of Real Colegio Complutense at Harvard for the Visiting Scholar Grant. This work was performed in part at the Center for Nanoscale Systems (CNS), a member of the National Nanotechnology Infrastructure Network (NNIN), which is supported by the National Science Foundation under NSF Award No. ECS-0335765. CNS is part of Harvard University. G.J.S. would like to acknowledge the financial support of the National Science Foundation Graduate Research Fellowship.

\section{References}

[1] Rho WY, Jeon H, Kim HS, Chung WJ, Suh JS, Jun BH. Recent progress in dyesensitized solar cells for improving efficiency: $\mathrm{TiO}_{2}$ nanotube arrays in active layer. $\mathrm{J}$ Nanomater 2015: Article ID 247689: 1-17. http://dx.doi.org/10.1155/2015/247689 [2] Matos BR, Isidoro RA, Santiago EI, Tavares AC, Ferlauto AS, Muccillo R et al. Nafion-titanate nanotubes composites prepared by in situ crystallization and casting for direct ethanol fuel cells. Int J Hydrogen Energy 2015:40: 1859-67.

[3] Jang NS, Kim MS, Kima SH, Lee SK, Kim JM. Direct growth of titania nanotubes on plastic substrates and their application to flexible gas sensors. Sens Actuators B 2014:199:361-68.

[4] Mohamed AM, Aljaber AS, AlQaradawi SY, Allam NK. $\mathrm{TiO}_{2}$ nanotubes with ultrathin walls for enhanced water splitting. Chem Comm 2015:51:12617-20.

[5] Liu L. Efficient water oxidation using $\alpha-\mathrm{Fe}_{2} \mathrm{O}_{3}$ thin films conformally coated on vertically aligned titania nanotube arrays by atomic layer deposition. Mater Lett 2015:159:284-288.

[6] Khan MA, Kang YM. Catalytic properties of titania nanotube prepared by simple refluxing method. Mater Lett 2014:116:160-63.

[7] Podporska-Carroll J, Panaitescu E, Quilty B, Wang LL, Menon L, Pillai SC. Antimicrobial properties of highly efficient photocatalytic $\mathrm{TiO}_{2}$ nanotubes. Appl Catal B Environ 2015:176:70-75.

[8] Zhang M, Wei M, Wang D, Duan Y. Preparation and characterization of a drug vehicle: Polymer brush immobilized Ag nanoparticles onto titanium nanotubes. Mater Lett 2014:135:51-4.

[9] Damodaran VB, Bhatnagar D, Leszczak V, Popat KC. Titania nanostructures: a biomedical perspective. RSC Adv 2015:5:37149-71.

[10] Pang YL, Lim S, Ong HC, Chong WT. A critical review on the recent progress of synthesizing techniques and fabrication of $\mathrm{TiO}_{2}$-based nanotubes photocatalysts. Appl Catal A Gen 2014:481:127-42. 
[11] Zwilling V, Darque-Ceretti E, Boutry-Forveille A, David D, Perrin MY, Aucouturier M. Structure and physicochemistry of anodic oxide films on titanium and TA6V alloy. Surf Interface Anal 1999:27:629-37.

[12] Regonini D, Bowen CR, Jaroenworaluck A, Stevens R. A review of growth mechanism, structure and crystallinity of anodized $\mathrm{TiO}_{2}$ nanotubes. Mater Sci Eng 2013:74:377-406.

[13] Haring A, Morris A, Hu M. Controlling morphological parameters of anodized titania nanotubes for optimized solar energy applications. Mater 2012:5:1890-909.

[14] Yashwanth IVS, Gurrappa I. The effect of titanium alloy composition in synthesis of titania nanotubes. Mater Lett 2015:142:328-31.

[15] Manovah David T, Wilson P, Ramesh C, Sagayaraj P. A comparative study on the morphological features of highly ordered titania nanotube arrays prepared via galvanostatic and potentiostatic modes. Curr Appl Phys 2014:14:868-75.

[16] Galstyan V, Vomiero A, Concina I, Braga A, Brisotto M, Bontempi E, et al. Vertically aligned $\mathrm{TiO}_{2}$ nanotubes on plastic substrates for flexible solar cells. Small 2011:7:2437-42.

[17] Xin Q, Gao Y, Wu X, Li C, Liu T, Shi Y, et al. Incorporating one-dimensional aminated titania nanotubes into sulfonated poly(etheretherketone) membrane to construct $\mathrm{CO}_{2}$-facilitated transport pathways for enhanced $\mathrm{CO}_{2}$ separation. J Membr Sci 2015:488:13-29.

[18] Liu G, Wang K, Hoivik H, Jakobsen H. Progress on free-standing and flowthrough $\mathrm{TiO}_{2}$ nanotube membranes. Solar Energy Mater \& Solar Cells 2012:98:24-38.

[19] Kant K, Losic D. A simple approach for synthesis of $\mathrm{TiO}_{2}$ nanotubes with throughhole morphology. Phys Status Solidi 2009:3139-141.

[20] Wang D, Liu L. Continuous fabrication of free-standing $\mathrm{TiO}_{2}$ nanotube array membranes with controllable morphology for depositing interdigitated heterojunctions. Chem Mater 2010:22:6656-64.

[21] Adán C, Marugán J, Sánchez E, Pablos C, van Grieken R. Understanding the effect of morphology on the photocatalytic activity of $\mathrm{TiO}_{2}$ nanotube array electrodes.

Electrochim Acta, 2016 (in press, http://dx.doi.org/10.1016/j.electacta.2016.01.088).

\section{Figure Captions}

Figure 1. Time profiles of current and voltage during the anodization of samples to obtain transferred arrays of closed and open TNT.

Figure 2. Photograph of a TNT array before (left) and after (right) the transfer to the polymer. 
Figure 3. SEM images of the transferred TNT arrays produced after a decrease in the current intensity, a) and b), a short increase in the current intensity, c) and d), and a increase of the current intensity for an optimal duration for tube opening, e) and f). Figure 4. Schematic representation of the procedure for preparing the tailored hybrid polymer-TNT materials (see details in text). 